\title{
The use of cross-sectional echocardiography in a general hospital
}

\author{
Allen K. Brown \\ F.R.C.P.
}

\author{
VALERIE ANDERSON \\ M.B., Ch.B.
}

\author{
Cardiac Investigation Department, Royal Lancaster Infirmary, Lancaster
}

\begin{abstract}
Summary
Three hundred and five patients routinely referred to a general hospital were surveyed to assess the advantages of cross-sectional echocardiography (CSE) over the conventional $M$ mode method. CSE provided a dynamic display of the movement of the heart, particularly left ventricular function, and facilitated the location of cardiac structures. It was valuable in assessing the degree of mitral stenosis and the type of left ventricular outflow obstruction. Mitral valve prolapse, pericardial effusion, intracardiac tumours and congenital heart disease were more easily diagnosed than by $M$ mode techniques, but the origin of the basal systolic murmur still remained a problem.

It was concluded that the 2 systems were complementary, and that CSE provided important additional information which improved the diagnostic capability of echocardiography.
\end{abstract}

\section{Introduction}

Cross-sectional echocardiography (CSE) is reported to have advantages over conventional $\mathbf{M}$ mode echocardiography in the diagnosis and assessment of a variety of congenital and acquired cardiac disorders (Roelandt, 1975; Feigenbaum, 1976). Most reports of CSE come from major cardiac centres with many cases undergoing specialized investigation before surgery. The spectrum of disease which presents to general medical units includes a high proportion of patients referred for primary diagnosis of cardiac disease, many with minor lesions. The purpose of this study is to assess the value and limitations of CSE in the management of patients from the medical wards and out-patient clinics of a general hospital.

\section{Materials and methods}

The instrument used in this study was a commercially available $30^{\circ}$ sector scanner (Smith Kline Instruments Eko-Sector I). Images were viewed in real time during the examination or later from videotape recordings, and still photographs were obtained from single frames using a Polaroid camera.

Patients were referred from the general medical and paediatric departments of the Royal Lancaster
Infirmary and the Westmorland County Hospital. A total of 305 subjects (152 male, 153 female) were investigated in the first year. Patients investigated in the Coronary Care Unit were excluded from this review.

Cross-sectional studies were performed in either the supine or left lateral position. Long axis parasternal views were used to assess the thickness and movement of the mitral valve in mitral stenosis, and the area of the mitral valve orifice was measured using short axis views. The position of the probe was altered until the smallest orifice was seen. Using a stop frame from the video-tape recording, the internal location cursor was adjusted so that there was exactly one $\mathrm{cm}$ between the markers. The valve orifice was then traced on a transparent plastic sheet and measured with graph paper. Alternatively, it was measured directly on the screen using a graticule.

Images of the aortic root and valve, interventricular septum, left ventricle, left atrium, tricuspid valve, pulmonary valve and right ventricular outflow tract were assessed from long and short axis parasternal views.

The cardiac apex was located by palpation and, using the short axis position and directing the probe towards the base of the heart, a four chamber view of both atria and ventricles and the interatrial and interventricular septa was obtained. The transducer was then angled in a lateral direction to obtain short and long axis views of the apex of the left ventricle. The body of the left ventricle was subsequently viewed by moving the transducer medial to the apex beat.

Additional views from the suprasternal notch and subxiphoid region were used when indicated.

\section{Results \\ Mitral valve disease \\ Sixty-five patients (19 male, 46 female) were investigated (Table 1). Forty-three patients, including 11 post-valvotomy subjects, were examined to assess the severity of mitral stenosis using short axis views (Fig. 1), the mitral valve orifice area could be meas- ured in $51 \%$ of subjects (range $0.6 \mathrm{~cm}^{2}$ to $2.8 \mathrm{~cm}^{2}$ ).}


TABLE 1. Summary of the findings in a group of 305 patients referred to the Medical Unit of a general hospital. The figures in parenthesis refer to the total in the group. The figures on the right refer to numbers of patients

\begin{tabular}{llr}
\hline Mitral valve disease (65) & Mitral stenosis & 32 \\
& Post-valvotomy & 11 \\
& Systolic click and murmur & 11 \\
& Atrial fibrillation & 11 \\
Left ventricular outflow tract obstruction (64) & Acquired valvar aortic stenosis & 51 \\
& Congenital domed valve & 6 \\
Possible left ventricular aneurysm (21) & Hypertrophic obstructive cardiomyopathy & 7 \\
(inadequate recordings-2) & Persistent elevation of ST segment, post-infarction & 7 \\
& (aneurysm suggested in 5) & 12 \\
Obscure heart disease (39) & Unstable angina or cardiac failure post-infarction \\
Congenital heart disease (21) & (aneurysm suggested in 4) & \\
& See Table 2 & 6 \\
& Atrial septal defect & 10 \\
& Ventricular septal defect & 2 \\
Mid-systolic murmur (62) & Tetralogy of Fallot & 1 \\
(inadequate recordings-2) & Hypoplastic left heart syndrome & 1 \\
& Transposition & 1 \\
Miscellaneous (33) & Severe valvar pulmonary stenosis & 49 \\
\hline & No abnormality detected & 4 \\
& Acquired valvar aortic stenosis & 1 \\
& Congenita aortic stenosis & 5 \\
& Pulmonary stenosis & 1 \\
& Mitral valve prolapse & See Table 3 \\
\end{tabular}

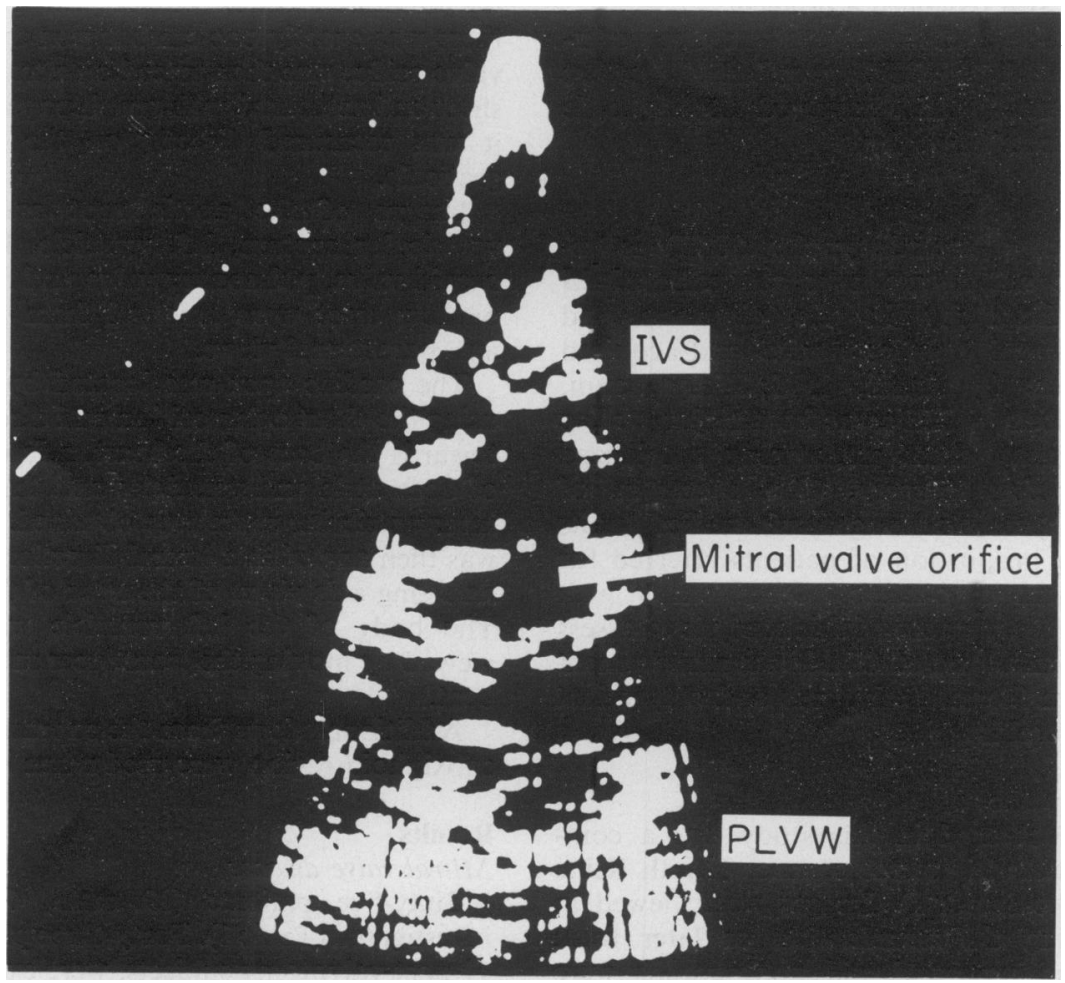

FIG. 1. Short axis view of the mitral valve showing valve orifice in a patient with mitral stenosis. (IVS, interventricular septum; LV, left ventricle; PLVW, posterior left ventricular wall). 
Difficulty in measuring the area in the other patients resulted from an inability to obtain an adequate record of both leaflets simultaneously. Long axis views showed restricted mobility and thickening of the mitral valve leaflets in these patients.

Of the remaining 22 patients, 11 were investigated because of a systolic click and murmur (9) or a systolic click alone (2). Mitral valve prolapse was demonstrated in 6 subjects, 3 with posterior leaflet prolapse and 3 with both anterior and posterior leaflet prolapse. Four subjects had normal echocardiograms and these included both patients with the systolic click. The recordings in the final patient in this group were inadequate for full analysis of leaflet movement. Mitral stenosis was found in 2 of the 11 patients with atrial fibrillation; one of these had clinical evidence of mitral stenosis (a short mid diastolic murmur and an opening snap were recorded on a phonocardiogram) but the other patient had no abnormal auscultatory signs.

\section{Left ventricular outflow tract obstruction}

Sixty-four patients (46 male, 18 female) were referred because of basal systolic murmurs and evidence of left ventricular hypertrophy (Table 1). Valvar obstruction was characterized by limited leaflet movement and a mass of echoes at valve level in the aortic root. These dense echoes tended to obscure leaflet movement but at least one leaflet was seen on long axis in $88 \%$ of cases and the leaflets remained within the lumen of the aortic root. In normal subjects the linear echoes lie parallel to the walls of the aorta in systole where they merge with the walls. Patients with a low cardiac output showed failure of the leaflets to appose to the aortic walls but were distinguished from patients with aortic stenosis by the normal appearance of the leaflets and the absence of dense echoes. The domed, thickened leaflets typical of congenital aortic stenosis were readily recognized on cross-sectional studies, but $M$ mode echocardiograms were better than CSE for identifying hypertrophic obstructive cardiomyopathy.

\section{Left ventricular aneurysms}

A total of 21 patients (15 male, 6 female) were investigated because of possible left ventricular aneurysm (Table 1). Of the 9 subjects with aneurysms suggested by cross-sectional studies, discrete apical areas of abnormal wall motion were detected in 7 , and the apex plus the anterior wall were involved in 2 patients (Fig. 2a, b). Confirmation of the site of the aneurysm by left ventricular angiography was obtained in 4 cases.

The remaining 10 patients showed generalized poor left ventricular wall motion and these abnormal features persisted in 3 of those who were reinvestigated after a period of intensive medical therapy. Invasive cardiac investigations were avoided in these patients.

\section{Obscure heart disease}

The 39 patients ( 23 male, 16 female) who were referred with clinical evidence of heart disease but no obvious cause were sub-divided into 2 groups (Table 2). Cross-sectional studies were largely

TABle 2. Eventual diagnosis in patients presenting with obscure heart disease

Group I. Large heart with or without failure:

Intracardiac tumour

Congestive cardiomyopathy

Presumed ischaemic/hypertensive heart disease

Pulmonary heart disease

No abnormality shown

Group II. Abnormal chest X-ray/ECG or dyspnoea and chest pain:

Ischaemic heart disease

Pulmonary thromboembolic disease

Pericardial cyst

Asymmetric septal hypertrophy

No definite heart disease

\begin{tabular}{ll} 
No definite heart disease & 14 \\
\hline
\end{tabular}

unhelpful in these patients, apart from the 2 patients with left atrial tumours which were readily and quickly recognized (Fig. 3). In the patient with the provisional diagnosis of pericardial cyst, the boundaries and relationships of a large echo-free space lateral to the right ventricle was clearly demonstrated, but confirmation was not obtained because the patient refused further investigation.

\section{Congenital heart disease}

Twenty-one patients ( 9 male, 12 female) were investigated (Table 1). These patients were referred to broaden the experience of the echocardiographers rather than for primary cardiac diagnosis, hence 13 patients were studied after diagnosis had been made by cardiac catheterization, and 3 were referred following surgical correction of a defect. Of the 6 patients with atrial septal defects (ASDs), 3 had secundum defects with insignificant shunts on cardiac catheterization and the echocardiograms were normal. Two patients with Eisenmenger ASDs showed increased right ventricular dimensions, and one of these had bidirectional shunting on angiography which was confirmed by to and fro movement of 'microbubbles' across the defect on 4-chamber view cross-sectional contrast imaging. The final patient in this group was investigated after repair of a primum defect and mitral leaflet prolapse was shown on CSE. Poor recordings were obtained from 

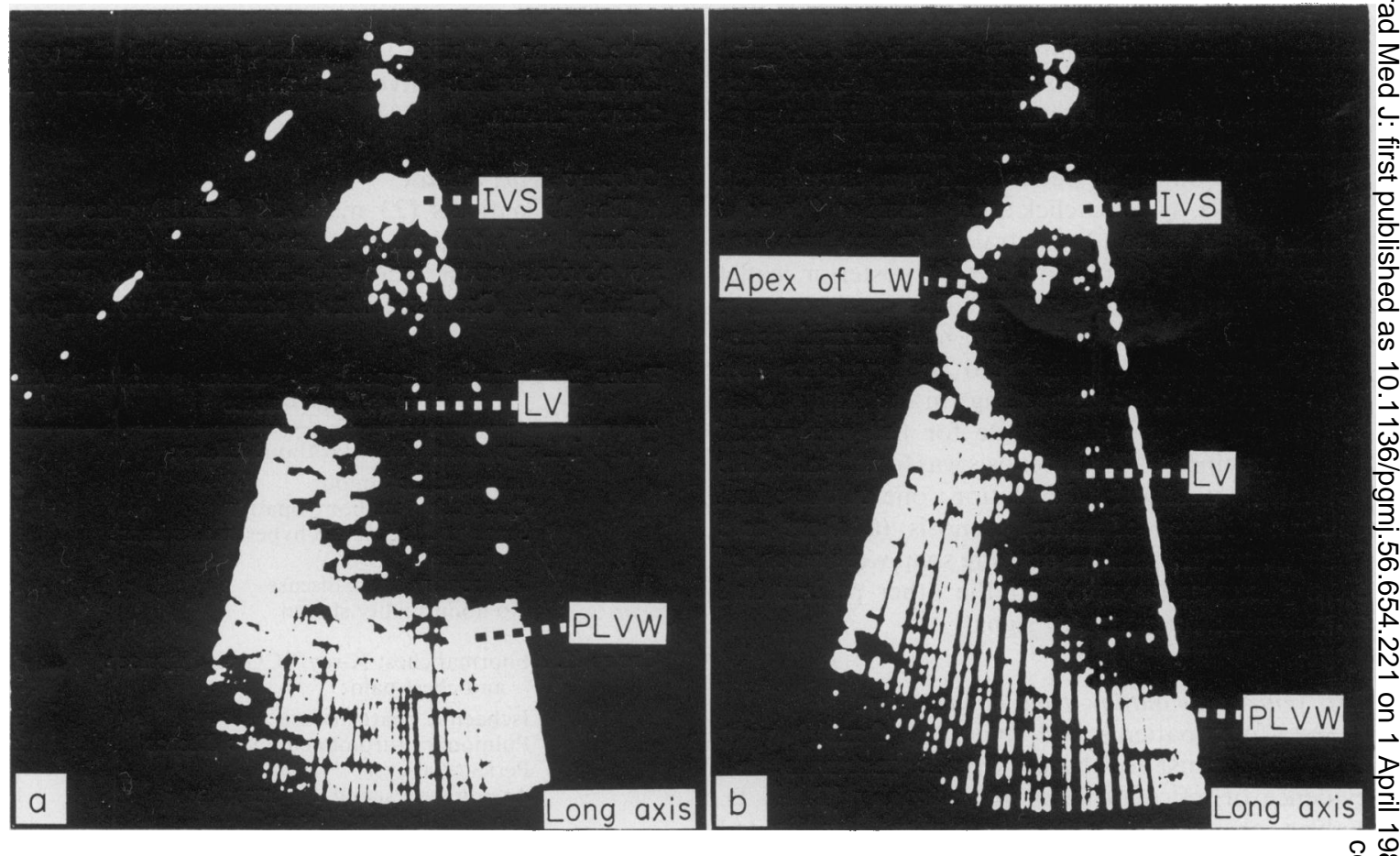

F1G. 2. Long axis view of the apex of the left ventricle in a patient with an apical aneurysm, (a) systole, (b) diastole을 (IVS, interventricular septum; LV, left ventricle; PLVW, posterior left ventricular wall).

one patient with an Eisenmenger ventricular septal defect (VSD), the site of the septal patch was visualized in one patient following repair of a VSD and the remaining patient showed the appearance of diastolic microbubbles in the left ventricle.

Of the 2 patients with Fallot's tetralogy, one was investigated after total correction and the crosssectional studies showed an intact ventricular septum and a normal-looking right ventricular outflow tract and pulmonary valve; the other was a 9-month-old male with Down's syndrome and cyanotic heart disease. Echocardiography showed normal relations of the great vessels but the interventricular septum and pulmonary valve were inadequately visualized. The patient with a Dtransposition had atrial and ventricular septal defects, pulmonary atresia and patent ductus arteriosus on cardiac catheterization. The cross-sectional echocardiogram showed a single atrio-ventricular valve, and only one ventricular chamber and one great vessel were recorded. Cross-sectional studies demonstrated thickened pulmonary valve leaflets which remained fixed in the lumen during systole in the patient with severe valvar pulmonary stenosis. Although the left ventricle was not clearly seen in the patient with hypoplastic left heart syndrome, it was uncertain whether this was due to technical

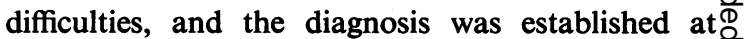
cardiac catheterization.

Before studying these patients, the authors experi-을 mented with different techniques to obtain contrast echocardiograms, and the most reliable methodo proved to be the fast injection of normal saline through a 19 gauge butterfly needle via the right 3 . antecubital fossa. Blood from the patient was almosto as good as normal saline, and indocyanine green $\overline{3}$. had no advantage and was expensive. Since using theo standardized method there have been 3 failures in 16 consecutive contrast studies.

Mid-systolic murmurs

Sixty-two patients (20 male, 42 female) were referred with basal mid-systolic murmurs and were. included in this group if chest X-ray and electro- N cardiograph were normal (Table 1). Thirteen of the N female patients were investigated after a murmuro had been noted during pregnancy. Adequate cross 0 sectional views of aortic and pulmonary valves were obtained in all but 2 patients.

\section{Miscellaneous}

Thirty-three patients (18 male, 15 female) were

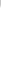




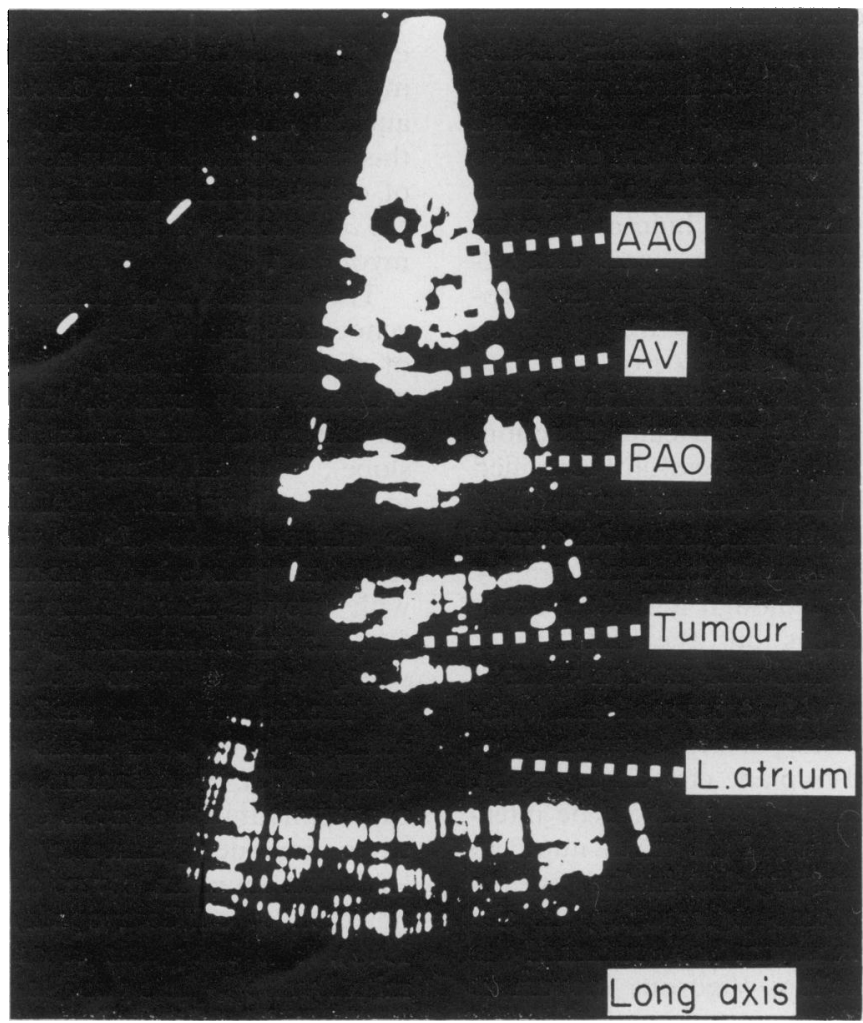

FIG. 3. A long axis view showing the tumour in the left atrium. (AAO, anterior aortic root; PAO, posterior aortic root; $\mathrm{AV}$, aortic valve leaflets).

included in this group (Table 3). The presence of pericardial effusion was rapidly and clearly demonstrated by cross-sectional echocardiography in all 10 patients, and serial studies showed the effect of treatment. One of these patients with a haemopericardium provided a dramatic image of the 'swinging heart' on CSE.

The cross-sectional long axis views of the aortic valve in the patients with aortic regurgitation showed a characteristic, rapid superior-inferior motion of the leaflets in diastole, and the hyperdynamic motion of the dilated left ventricle was appreciated.

TABLE 3. The reasons for echocardiography in a miscellaneous group of patients

Pericardial effusion

Aortic regurgitation

Tricuspid regurgitation

Systemic emboli

Vascular disease

Myocardial infarction

Angina after coronary artery bypass grafting

Prosthetic valves
Apical views of the right ventricle with peripheral intravenous injection of normal saline were used to obtain contrast echocardiograms in 2 of the 4 patients with tricuspid regurgitation and prolonged to and fro movement of contrast over the tricuspid valve was demonstrated. In one of these patients, it was not possible to get adequate images from the subxiphoid region.

The 2 patients referred with possible aortic dissection had normal cross-sectional images of the ascending and proximal descending aorta using suprasternal views and were subsequently proved to have no significant aortic disease. Cross-sectional studies were unhelpful in the remaining 10 patients.

\section{Discussion}

Conventional $\mathrm{M}$ mode echocardiography provides information on the motion of the heart and intracardiac structures and allows measurement of axial dimensions. Relative movement of different structures is difficult to judge when motion is at an 
angle to the sound beam axis and the resultant images bear little resemblance to familiar cardiac anatomy. Real time cross-sectional imaging provides a recognizable display of cardiac structures, and lateral relationships are displayed so that the shape and size, as well as the relative motion, of structures can be appreciated. Details of a technique for complete ultrasonic examination of the heart using 2dimensional real time echocardiography are provided in the report by Tajik et al. (1978).

The spatial orientation provided by cross-sectional echocardiography permits the localization of discrete areas of abnormal left ventricular function. The cross-sectional technique successfully identified the site of abnormal left ventricular motion in $100 \%$ of 31 cases of wall aneurysm compared with correct diagnosis in $48 \%$ using $\mathrm{M}$ mode echocardiography (Weyman et al., 1976c), although a further study (Kisslo et al., 1977) points out the difficulty of defining abnormal left ventricular motion without considerable experience with cross-sectional techniques, and discusses discrepancies between diagnoses made by CSE and bi-plane ciné-angiography. The results in the present subjects should be interpreted with caution in view of the small numbers involved but it is encouraging that in the patients who have progressed to ciné-angiography, the site of the left ventricular aneurysm has confirmed the echocardiographic prediction. Vigorous movement of the 'normal' myocardium contrasts with the poor movement of the aneurysm and may seem to 'point' to the abnormal area and should always lead to a careful search for an aneurysm. The authors avoid invasive investigation of subjects with poor generalized left ventricular wall motion but repeat cross-sectional recordings are reviewed after intensive medical treatment.

Cross-sectional echocardiography is superior to the $M$ mode technique in localizing the site of obstruction in patients with left ventricular outflow tract disease (Weyman et al., 1976a; Williams, Sahn and Friedman, 1976). Two varieties of valvar aortic stenosis are recognized. Calcific stenosis shows thickened aortic valve leaflets with limited mobility and a mass of echoes at valve level in the aortic lumen. The authors have not attempted to assess the severity of valve obstruction; although measurements of cusp separation in systole have given a good approximation of the degree of stenosis (Weyman et al., 1975), doubt has been thrown on the validity of such measurements to assess the degree of obstruction (Chang, Clements and Chang, 1977). The congenital domed valve is easily recognized by crosssectional studies, whereas $M$ mode echocardiograms may show an apparently normal aortic valve if the echo beam passes through the apex of the dome.

Although others have demonstrated the value of
CSE in the diagnosis of supravalvar (Weymanڤ et al., 1978a) and fixed subvalvar aortic stenosis (Wey- 3 man et al., 1976c; Ten Cate et al., 1979), the present $\stackrel{\odot}{\circ}$ authors have no patients with either lesion in $ᄃ$ this series, and they have not found any disadvantage $\overrightarrow{\vec{c}}$ of cross-sectional imaging over $\mathbf{M}$ mode studies in the diagnosis of hypertrophic obstructive cardio- $\frac{-}{0}$ myopathy.

The diagnosis of mitral stenosis by $M$ mode $\frac{\vec{\sigma}}{\sigma}$ echocardiography depends on reduced amplitude $\varrho$ of the anterior leaflet, thickened leaflets, anterior diastolic movement of the posterior leaflet and $\vec{O}$ diminished anterior mitral leaflet closing rate $(\mathrm{E}-\mathrm{F}-\overrightarrow{-}$ slope). The amplitude of motion reduces deeperc్ in the left ventricle, leaflet thickness may vary $\frac{\Omega}{0}$ in different parts of the valve and the posterior $\frac{}{3}$ leaflet may move in the normal direction in patients with proved mitral stenosis and hence all these 9 features can be misleading. The E-F slope has been of widely used to assess the severity of mitral valve obstruction but the method is insensitive and attempts have been made to improve sensitivity $\overrightarrow{0}$ (Shiu, 1977). Furthermore, other conditions which can mimic mitral stenosis by producing a slow $\mathrm{E}_{-} \mathrm{F}_{\vec{D}}$ slope include pulmonary arterial hypertension, 을. left atrial myxoma, severe aortic stenosis and nonobstructive cardiomyopathy (McLaurin et $a \mathscr{B}, \infty$ 1973). The long axis cross-sectional view of the. mitral valve leaflets enables close inspection of the pattern of leaflet motion and the typical 'bowin of the anterior leaflet, and the extent of leaflet thickening is readily appreciated. The use of short axis views to measure the size of the mitral valve $\stackrel{\varnothing}{\propto}$ orifice correlates well with operative and catheter $\overrightarrow{\vec{P}}$ estimates (Henry et al., 1975a; Nicol, Gilbert and $\frac{\rho}{3}$ Kisslo, 1977; Wann et al., 1978a).

Although short axis cross-sectional studies have been used recently to detect significant rheumatic mitral regurgitation (Wann et al., 1978b) echocardio- 3 . graphy has been used mainly in the clarification of 0 mitral regurgitation due to mitral valve prolapse 3 . (Leading Article, 1979). The present results suggest $\delta$ that CSE is valuable in the diagnosis of prolapse of $₹$ both mitral leaflets, particularly the anterior.

The value of $\mathbf{M}$ mode echocardiography in the diagnosis of pericardial effusion and intracardiac tumours, in particular left atrial myxoma, is attested $\frac{N}{N}$. by reports from early days in the use of the technique? (Feigenbaum, Waldhausen and Hyde, 1965; Effert 0 and Domanig, 1959). Pericardial effusion is readily recognized with careful $\mathbf{M}$ mode recording buto the authors have been impressed with the rapidity and ease of detection using CSE and the 'swinging heart' is dramatically visualized on real time cross- $\stackrel{f}{?}$ section imaging. Appreciation of the size, shape, 7 movement and relations of intracardiac tumours is facilitated by cross-sectional echocardiography, $\stackrel{\mathbb{Q}}{\stackrel{\mathbb{Q}}{\Omega}}$ 
and CSE is more accurate than M mode echocardiography in differentiating a left atrial tumour from an extracardiac tumour compressing the left atrium (Yoshikawa et al., 1978).

A common problem in general hospital practice is the patient who presents with a basal systolic murmur and no specific X-ray or ECG abnormalities. Invasive studies are only justifiable in a small proportion of these patients, and echocardiography is the non-invasive technique most likely to provide specific diagnostic information. Aortic valve disease is demonstrated on CSE in all the patients in this study with clear radiation of the bruit into the neck, but similar abnormalities are shown in other patients although the systolic murmur is confined to the praecordium. Also, it is suspected that the low incidence of pulmonary stenosis in the present series represents under-diagnosis. Stenosis of the pulmonary valve of moderate or severe degree is suggested by a presystolic 'a' wave depth of greater than $8 \mathrm{~mm}$ on the posterior pulmonary leaflet by $\mathrm{M}$ mode echocardiography (Weyman et al., 1974). It is further suggested that CSE is more specific and sensitive, and subjects with minor gradients $(<50$ $\mathrm{mmHg}$ ) show typical doming of the pulmonary cusps (Feigenbaum, Weyman and Dillon, 1977; Weyman, 1977). In the present patients with minor pulmonary stenosis suspected on clinical and phonocardiographic grounds, the $\mathbf{M}$ mode studies show ' $\mathrm{a}$ ' waves of $6-10 \mathrm{~mm}$ but doming has not been demonstrated by cross-sectional imaging. In the single patient with severe valvar pulmonary stenosis, the pulmonary leaflets appear to 'stick' in the pulmonary artery but doming is not evident. An advantage of the cross-sectional technique is the ease with which the pulmonary valve is located, compared with the effort and time spent on trying to locate the valve with $\mathbf{M}$ mode echocardiography.

Cross-sectional echocardiography is particularly valuable in cyanotic congenital heart disease (Sahn et al., 1974; Henry et al., 1975b; Maron et al., 1975; Houston, Gregory and Coleman, 1977; Hagler et al., 1979) although the experience required in the diagnosis of complex defects limits the usefulness in general hospitals. Silverman and Schiller (1978) have used the 4-chamber view to detect septal defects and to define endocardial cushion defects, tricuspid atresia and Ebstein's anomaly, and the value of cross-sectional imaging has been demonstrated in supravalvar aortic stenosis and aortic hypoplasia (Weyman et al., 1978a), coarctation of the aorta (Weyman et al., 1978b), patent ductus arteriosus in infants and children (Sahn and Allen, 1978) and atrial septal defects (Kronik, Slany and Moesslacher, 1979; Fraker et al., 1979).

The authors conclude that real-time CSE has advantages over $\mathbf{M}$ mode techniques in the diagnosis of the site of left ventricular outflow tract obstruction, left ventricular aneurysms, pericardial effusion, intracardiac tumours, congenital heart lesions and, in the assessment of mitral valve disease, particularly the severity of mitral stenosis. Pollick (1978) has shown the value of $\mathbf{M}$ mode echocardiography in a district general hospital, and the authors have demonstrated that cross-sectional imaging increases the usefulness of echocardiography. The main limitation is the extra cost. This should be weighed against the enhanced diagnostic capability in patients who do not warrant invasive procedures, the avoidance of cardiac catheterization in some patients, the reduction in time taken to perform catheterization when echocardiograms have pinpointed specific problems which require further study, and the ability to observe the progress of cardiac disease or the results of surgery by repeated ultrasound studies.

\section{Acknowledgments}

We are grateful to the physicians who have allowed us to study patients in their care, and to Miss N. Stedman, $\mathrm{Mr}$ P. Harrison and Mr P. Nelson for technical assistance.

\section{References}

Chang, S., Clements, S. \& Chang, J. (1977) Aortic stenosis: Echocardiographic cusp separation and surgical description of aortic valve in 22 patients. American Journal of Cardiology, 39, 499.

EFFERT, S. \& Domanig, E. (1959) The diagnosis of intraatrial tumour and thrombi by the ultrasonic echo method. German Medical Monthly, 6, 1.

Feigenbaum, H., Waldhausen, J.A. \& Hyde, L.P. (1965) Ultrasound diagnosis of pericardial effusion. Journal of the American Medical Association, 191, 711.

Feigenbaum, H. (1976) Echocardiography, 2nd edn, Lea and Febiger, Philadelphia.

Feigenbaum, H., Weyman, A.E. \& Dillon, J.C. (1977) Cross-sectional echocardiographic visualization of the stenotic pulmonary valve. American Journal of Cardiology, 39, 279.

Fraker, T.D., Harris, P.J., Behar, V.S. \& Kisslo, J.A. (1979) Detection and exclusion of interatrial shunts by two-dimensional echocardiography and peripheral venous injection. Circulation, 59, 379.

Hagler, D.J., TaJik, A.J., Seward, J.B., MaIR, D.D. \& RITTER, D.G. (1979) Real-time wide-angle sector echocardiography: atrioventricular canal defects. Circulation, 59, 140.

Henry, W.L., Griffiths, J.M., Michaelis, L.L., McIntosh, C.L., Morrow, A.G. \& Epstein, S.E. (1975a) Measureof mitral orifice area in patients with mitral valve disease by real time two-dimensional echocardiography. Circulation, 51, 827.

Henry, W.L., Maron, B.J., Griffith, J.M., Redwood, D.R. \& EPSTEIN, S.E. (1975b) Differential diagnosis of anomalies of the great arteries by real-time two-dimensional echocardiography. Circulation, 51, 283.

Houston, A.B., Gregory, N.L. \& Coleman, E.N. (1977) Echocardiographic identification of aorta and main pulmonary artery in complete transposition. British Heart Journal, 40, 377. 
Kisslo, J.A., Robertson, D., Gilbert, B.W., von Ramm, O. \& BEHAR, V.S. (1977) A comparison of real-time, twodimensional echocardiography and cineangiography in detecting left ventricular asynergy. Circulation, 55, 134.

Kronik, G., Slany, J. \& Moesslacher, H. (1979) Contrast $M$ mode echocardiography in diagnosis of atrial septal defect in acyanotic patients. Circulation, 59, 372.

LEADING ARTICLE (1979) The floppy mitral valve. Lancet, i, 138.

McLaurin, L.P., Gibson, T.C., Waider, W., Grossman, W. \& CR'Aige, E. (1973) An appraisal of mitral valve echocardiograms mimicking mitral stenosis in conditions with right ventricular pressure overload. Circulation, 48, 801.

Maron, B.J., Henry, W.L., Griffith, J.M., Freedom, R.M., KELlY, D.T. \& EPSTEIN, S.E. (1975) Identification of congenital malformations of the great arteries in infants by real-time two-dimensional echocardiography. Circulation, 52, 671 .

Nichol, P.M., Gilbert, B.W. \& Kisslo, J.A. (1977) Twodimensional echocardiographic assessment of mitral stenosis. Circulation, 55120.

Pollick, C. (1978) Echocardiography in a district general hospital. Postgraduate Medical Journal, 54, 297.

RoelandT, J. (1975) Echocardiology. Current applications of echotechniques in cardiology. Heart Bulletin, 6, 9.

SAHN, D.J., Terry, R., O'Rourke, R., Leopold, G. \& FRIEDMAN, W.F. (1974) Multiple crystal cross-sectional echocardiography in the diagnosis of cyanotic congenital heart disease. Circulation, 50, 230.

SAHN, D.J. \& Allen, H.D. (1978) Real-time cross-sectional echocardiographic imaging and measurement of the patent ductus arteriosus in infants and children. Circulation, 58, 343.

ShIU, M.F. (1977) Mitral valve closure index. Echocardiographic index of severity of mitral stenosis. British Heart Journal, 39, 839.

Silverman, N.H. \& Schiller, N.B. (1978) Apex echocardiography. A two-dimensional technique for evaluating congenital heart disease. Circulation, 57, 503.

TAJIK, A.J., Hagler, D.J., MaIR, D.D. \& LIE, J.T. (1978) Two-dimensional real-time ultrasonic imaging of the heart and great vessels. Proceedings. Mayo Clinic, 53, 271.

Ten Cate, F.J., Van Dorp, W.G., Hugenholz, P.G. \& RoElandT, J. (1979) Fixed subaortic stenosis. Value of echocardiography for diagnosis and differentiation between various types. British Heart Journal, 42, 159.

Wann, L.S., Feigenbaum, H., Weyman, A.E. \& Dillon,
J.C. (1978a) Cross-sectional echocardiographic detection of rheumatic mitral regurgitation. American Journal of Cardiology, 41, 1258.

Wann, L.S., Weyman, A.E., Feigenbaum, H., Dillon, J.C. ® JoHNSTON, K.W. \& EgGleton, R.C (1978b) Determination $\subseteq$ of mitral valve area by cross-sectional echocardiography. Annals of Internal Medicine, 88, 337.

Weyman, A.E. (1977) Pulmonary valve echo motion inб clinical practice. American Journal of Medicine, 62, 843.

Weyman, A.E., Caldwell, R.L., Hurwitz, R.A., Girod, D.A., Dillon, J.C., Feigenbaum, H. \& Green, D. (1978a) Cross-sectional echocardiographic characterization of $\underset{\Omega}{\mathbb{D}}$ aortic obstruction. Supravalvular aortic obstruction and $\mathrm{W}$
aortic hypoplasia. Circulation, 57, 491.

Weyman, A.E., Caldwell, R.L., Hurwitz, R.A., Girod, $\overrightarrow{0}$ D.A., Dillon, J.C., Feigenbaum, H. \& Green, D. (1978b) Cross-sectional echocardiographic detection of $\vec{\omega}$ aortic obstruction. Coarctation of the aorta. Circulation, 57, 498.

Weyman, A.E., Dillon, J.C., Feigenbaum, H. \& Chang, S. (1974) Echocardiographic patterns of pulmonary valve motion in valvular pulmonary stenosis. American Journal of Cardiology, 34, 644.

Weyman, A.E., Feigenbaum, H., Dillon, J.C. \& Chang, S. O (1975) Cross-sectional echocardiography in assessing the severity of valvular aortic stenosis. Circulation, 52, 828. N

Weyman, A.E., Feigenbaum, H., Hurwitz, R.A., Girod, D.A., Dillon, J.C. \& ChANG, S. (1976a) Localization of 음 left ventricular outflow obstruction by cross-sectional $\rightarrow$ echocardiography. American Journal of Medicine, 60, 33.

Weyman, A.E., Feigenbaum, H., Hurwitz, R.A., Girod, D.A., Dillon, J.C. \& Chang, S. (1976b) Cross-sectional $\overrightarrow{0}$ echocardiography in evaluating patients with discrexe subaortic stenosis. American Journal of Cardiology, 连, 358.

Weyman, A.E., Peskoe, S.M., Williams, E.S., Dillon, J.G. \& Feigenbaum, H. (1976c) Detection of left ventricular aneurysms by cross-sectional echocardiography. Cir- $\overline{0}$ culation, 54, 936.

Williams, D.E., SAHN, D.J. \& Friedman, W.F. (1976) 응 Cross-sectional echocardiographic localization of sites of left ventricular outflow tract obstruction. American $\overline{\bar{O}}$ Journal of Cardiology, 37, 250.

Yoshikawa, J., Sabah, I., Yanagihara, K., OWaki, T., Kato, H. \& TANEmoto, K. (1978) Cross-sectional echocardiographic diagnosis of large left atrial tumor and extracardiac tumor compressing the left atrium. American $\overline{ }$ Journal of Cardiology, 42, 853. 